\title{
A Two Year Old Girl with Precocious Puberty: The Youngest Ever Age of Presentation
}

\author{
Authors \\ Shuchi Jain ${ }^{1}$, Shivi Jain ${ }^{2}$, Madhu Jain ${ }^{3}$ \\ ${ }^{1}$ Service Senior Resident, Department of Obstetrics \& Gynaecology \\ Email: shuchi.gyno81@gmail.com \\ ${ }^{2}$ Service Senior Resident, Department of Radiodiagnosis and Imaging, \\ Email: shivijain1103@gmail.com \\ ${ }^{3}$ Professor, Department of Obstetrics \& Gynaecology, \\ Email:drmadhujainbhu@gmail.com \\ Institute of Medical Sciences, Banaras Hindu University, Varanasi, India \\ Corresponding Author \\ Dr. Madhu Jain \\ G-11, Lal Bahadur Shashtri Nagar Colony, Karaundi,Varanasi, India \\ Email-drmadhujainbhu@gmail.com, Mobile No.-+919415302988
}

\begin{abstract}
Introduction: Precocious means developing unusually early.Precocious puberty is onset of puberty before 8 year in girls and 9 year in boys. ${ }^{1}$ When it is because of premature activation of hypothalamic pituitary axis, it is called central or complete precocious puberty. If it results from ectopic gonadotropin secretion, it is called peripheral precocious puberty. We hereby present a two year old menstruating girl with precocious puberty as a rare presentation.
\end{abstract}

Case Presentation: A two year old baby girl was brought by her parents to Gynecology outpatient department with complaint of per vaginal bleeding. On examination, her pubic and axillary hair, and breast were developed with Tanner stage 2 and 4 respectively. Her routine blood investigations and hormone profile were normal except increased level of Dehydroepiandrosterone. X-ray of her distal radio-ulnar joint and MRI scan of her brain were normal. On ultrasonography, a mass was visible $(5.5 \times 5.4 \mathrm{~cm})$ in left adrenal gland which was confirmed by $C T$ scan $(5.2 \times 3.9 \mathrm{~cm})$.

Conclusion: Hereby, we report an extremely rare case of peripheral precocious puberty with Tanner Stage 4 breast development and pubic hair (Tanner Stage 2) in a menstruating two year old girl due to benign adrenal adenoma.

Key words: Precocious puberty, Pseudo-precocious puberty, Peripheral precocious puberty, Adrenal adenoma. 


\section{INTRODUCTION}

Puberty is the process by which sexually immature person becomes capable of reproduction. Precocious puberty is onset of puberty before $8 \mathrm{yrs}$ in girls and $9 \mathrm{yrs}$ in boys ${ }^{[1]}$ New guidelines recommend that puberty be considered precocious only when pubic hair and breast appear before age of $7 \mathrm{yrs}$ in white girls and 6 yrs in black girls. ${ }^{[2]}$

\section{CASE REPORT}

The parents of a two year old baby girl brought her to Gynecology outpatient department with complaint of per vaginal bleeding. On examination, her pubic hair \& axillary hair, and breast were developed with Tanner stage 2 and 4 respectively (Fig.1\& 2). Her routine blood investigations and hormone profile were normal except increased level of Dehydroepiandrosterone (DHEA, $66 \mu \mathrm{gm} / \mathrm{dl})$. X-ray of her distal radioulnar joint and MRI scan of her brain were normal. On ultrasonography, a mass of $5.5 \times 5.4$ $\mathrm{cm}$ was visible in left adrenal gland with downward shift in the ipsilateral kidney. It was confirmed by CT scan and was found to measure $5.2 \times 3.9 \mathrm{~cm}$ (Fig. 3 ).

The left Adrenal gland along with tumor was resected with perioperative cortisol replacement. Diagnosis of adrenal adenoma was confirmed on histopathological examination (Fig.4). The patient is under regular follow-up with mineral corticoid replacement therapy.

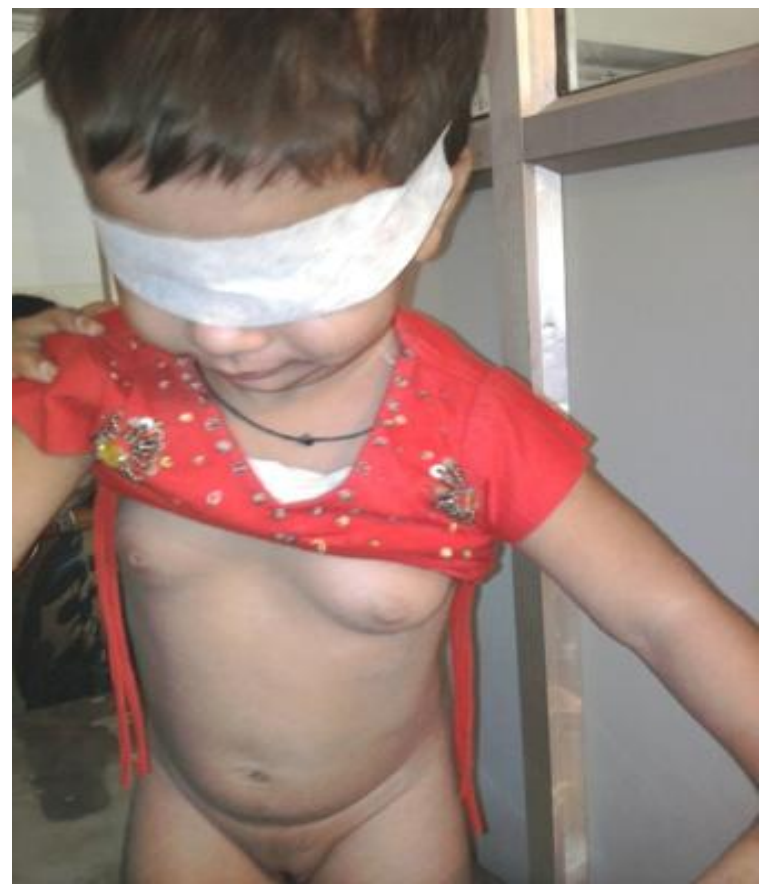

FIGURE 1: A 2 year old child showing Tanner stage 4 development of breast, and stage 2 pubic hair

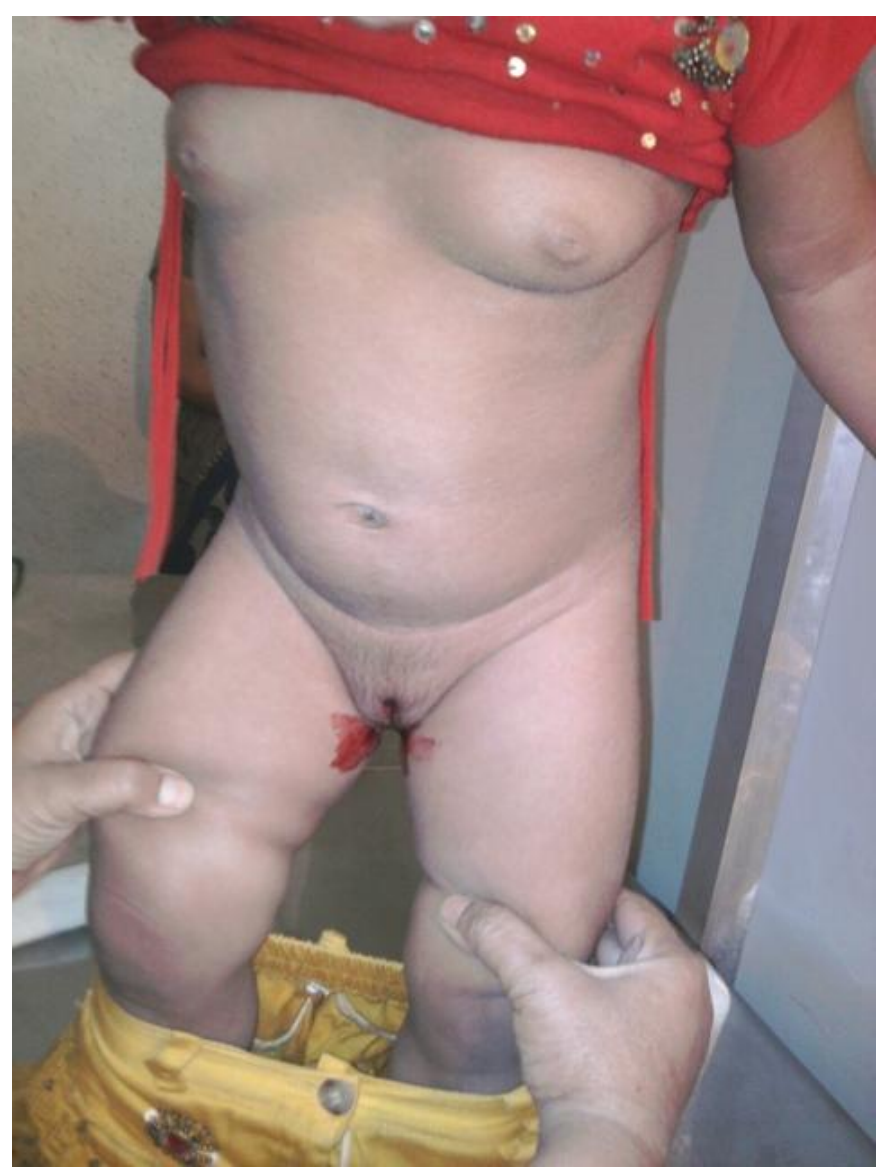

Figure 2: Same child while menstruating. 


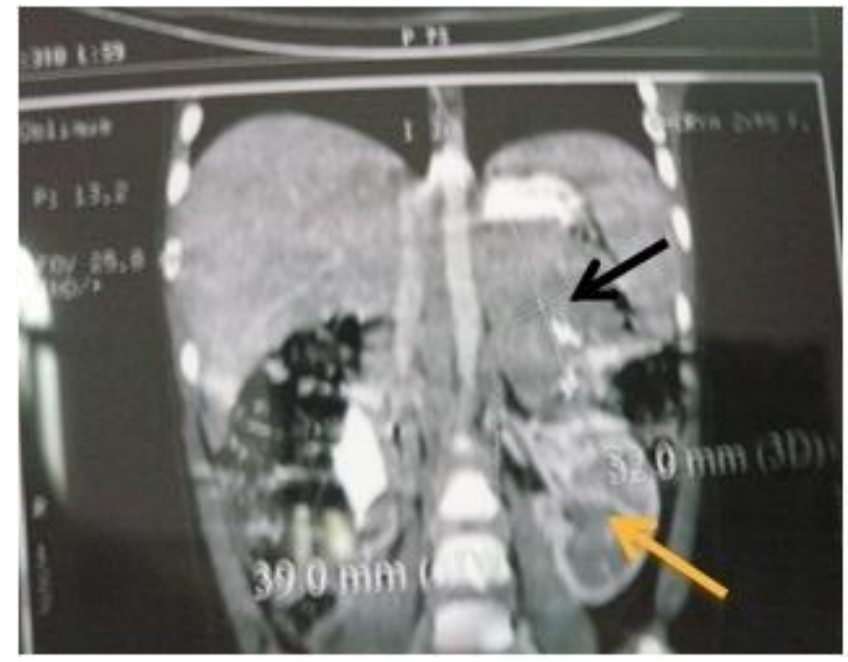

FIGURE 3: CT Abdomen showing Adrenal mass (black arrow, $52 \mathrm{~mm} \times 39 \mathrm{~mm}$ ) with downward shift of kidney, yellow arrow.

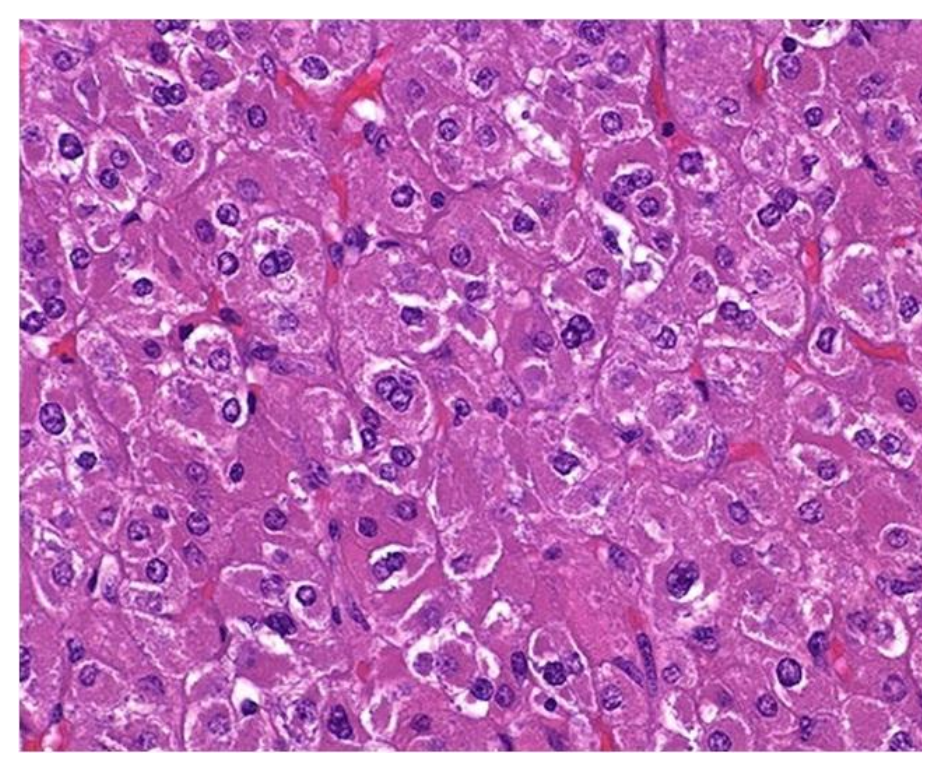

Figure 4: Histopathology showing features of adenoma of Adrenal gland.

\section{DISCUSSION}

Precocious puberty may be central, peripheral and combined. When it results from premature reactivation of hypothalamic Leutinizing hormone releasing hormone (LHRH), it is called true or central precocious puberty ${ }^{[3,4]}$ If it results from extrapituitary secretion of gonadotropin or gonadal steroid independent of pulsatile LHRH stimulation, it is called pseudoprecocious puberty or peripheral precocious puberty as in our case ${ }^{[3,4]}$
Combined central and peripheral precocity, sets in with the peripheral production of sex steroid secondary to the activation of hypothalamo pituitary axis.

There may be some problems with early onset of puberty. Whereas the initial growth spurt can cause tall stature, early bone maturation in precocious puberty can cause linear growth to cease too early and result in short stature. The early appearance of breast and menstruation in girls and increased libido in boys can cause emotional distress in young children with social implications.

Gonadotropin independent precocious puberty is much less common in girls. It can occur due to ovarian or adrenal tumors. Adrenal tumor rarely causes feminization $(10 \%)$. ${ }^{[5]}$ When feminization and virilisation coexist, presentation is identical to true precocious puberty as in our case. Feminizing tumor is almost always malignant with equal preference of left and right side ${ }^{[6]}$ Such a tumor larger than $6 \mathrm{~cm}$ is almost always malignant. Definitive treatment of benign adrenal adenoma is surgical resection of adenoma along with adrenal gland. It is usually curative. Cortisol replacement is almost always needed perioperatively.

\section{CONCLUSION}

Our case report strongly recommends for evaluating every case of precocious puberty on individual basis to find out its exact cause and institute early treatment to allow normal healthy life in a child.

\section{Learning points}

Although the feminizing adrenal tumors in children are invariably malignant, our patient had a benign adenoma. Feminizing adrenal adenoma is usually not associated with regular menstruation. Since the nature of the adrenal tumor was benign on histology, post-operative radiotherapy was not planned which otherwise is required for malignant tumors. 


\section{REFRENCES}

1. 'Precocious puberty' at Dorland's Medical Dictionary

2. Kaplowitz PB, Oberfield SE. Reexamination of the age limit for defining when puberty is precocious in girls in the United States: implications for evaluation and treatment. Drug and Therapeutics and Executive Committees of the Lawson Wilkins Pediatric Endocrine Society. Pediatrics 1999; 104 (4):936-941.

3. Khandekar S, Desh RJ. Clinical and hormonal studies in precocious puberty. Ind J Pediatr 1990; 57: 411-419.

4. Grunback M M, Dennis M. Puberty: Ontogeny, Neuroendocrinology, Physiology, and Disorder. In:Wilson JD, Foster DW, editors. William's textbook of Endocrinology. $8^{\text {th }}$ ed. Philadelphia.WB Saunders Company:1992. P. 1139-1222.

5. Norton JA, Le HN. Adrenal tumors. In: DeVita VT, Hellman S, Rosenberg SA, editors. Cancer Principles and practice of oncology. Philadelphia: Lippincott Williams and Wilkins: 2001.p.1770-1787.

6. Luton JP, Kuhn JM, de Gennes JL, Paulian B, Mahoudeau J, Laudat $\mathrm{MH}$, et al. Adrenal adenoma secreting exclusively estrogen in a woman during her reproductive period.11-yr follow up. Presse med 1984Jan 14; 13(1):23-26. 